\title{
Caulim: Características físicas e químicas de um marcador de consumo ideal
}

\author{
Caramelar, L.S. ${ }^{\circledR}$; Ribeiro, C.B. ${ }^{\text {; }}$ Morais, M.G. '; Carvalho, T.A. '; Costa, T.G. '; e Oliveira, L.O.F. ${ }^{2}$
}

Universidade Federal de Mato Grosso do Sul. Faculdade de Medicina Veterinária e Zootecnia. Campo Grande. Brasil.

${ }^{2}$ Centro Nacional de Pesquisa em Gado de Corte. EMBRAPA Gado de Corte. Campo Grande. Brasil.

PalaVRas ChaVe ADICIONAIS

Caulim.

Consumo de matéria seca.

Excreção fecal.

\section{RESUMO}

O objetivo da revisão foi descrever as características físicas e químicas do caulim, a fim de se conhecer a substância e propor como opção de marcador externo de consumo de matéria seca e excreção fecal de bovinos de corte em pastejo. Um marcador é considerado ideal quando apresenta características como ser inerte, não ser tóxico, não ter função fisiológica, não ser metabolizado, entre outras. Atualmente todos os marcadores possuem limitações, com isso pesquisas têm sido realizadas com intuito de descobrir um marcador que apresente todas esses atributos. Assim, o caulim destaca-se como interessante alternativa, pois além de fazer parte da nutrição dos animais, trata-se de um mineral cujas características evidenciam possível aplicação, como ser inerte em ampla faixa de $\mathrm{pH}(3$ a 9), fácil dispersão, baixa condutividade térmica e elétrica, baixo custo e boa resistência ao ataque químico por ácidos ou álcalis. Para a mensuração da substância via fezes, é preciso determinar a concentração de algum de seus elementos, ou seja, pelo fato do Al de estar presente nas forrageiras em concentração muito pequena, e metodologia analítica mais prática, leva a acreditar que este elemento é a escolha mais coerente. Conclui-se que o caulim características de um potencial marcador externo e pode ser quantificado com precisão nas fezes por meio do elemento alumínio.

\section{Kaolin: Physical and chemical characteristics to an ideal intake marker}

\section{SUMMARY}

\section{ADDITIONAL KEYWORDS}

Dry matter intake.

Fecal outuput.

Kaolin.

\section{INFORMATION}

\section{Cronología del artículo.}

Recibido/Received: 14.08.2020

Aceptado/Accepted: 29.12.2020

On-line: 15.04.2021

Correspondencia a los autores/Contact e-mail:

luana_caramala@@yahoo.com.br
The objective of the review was to describe the physical and chemical characteristics of kaolin in order to know the substance and to propose as an option for external marker of dry matter consumption and output fecal of beef cattle grazing. A marker considered ideal when it presents characteristics such as being inert, not being toxic, not having a physiological function, not metabolized, and others. Currently all markers have limitations, so research has been conducted in order to find a marker that presents all these characteristics. Thus, kaolin becomes an interesting alternative because it is part of animal nutrition and it is a mineral whose characteristics show the use, such as being inert ( $\mathrm{pH} 3$ to 9), easy dispersion, low thermal and electrical conductivity, low cost and good resistance to chemical by acids or alkalis. For the measurement of the substance via feces, it is necessary to determine the concentration of some of its elements, i.e., the fact that $\mathrm{Al}$ is present in forages in very small concentration, and practical analytical methodology, leads to believe that this element is the most coherent choice. It is concluded that kaolin characteristics of a potential external marker and can be accurately quantified in stool by means of the aluminum element.

\section{INTRODUÇÃO}

A determinação do consumo de alimentos apresenta grande importância na nutrição animal, pois permite relacionar a quantidade de nutrientes ingerida com o desempenho animal (Berchielli et al., 2011), e tem sido estimado por metodologias diretas e/ou indiretas.

Estimativas indiretas a partir do uso de marcadores vêm sendo aplicadas e gradativamente melhoradas no que se refere à acurácia dos resultados. Os marcado- res são substâncias indigestíveis, geralmente de fácil determinação, utilizadas como monitores químicos e físicos em processos digestivos e metabólicos (Owens \& Hanson, 1992). Contudo, todos os marcadores utilizados atualmente possuem limitações (Berchielli et al., 2006), especialmente em sua acurácia (Carvalho et al., 2007).

Assim, os estudos tem buscado um marcador de fácil manipulação e aplicação no campo, que não re- 
presente riscos à saúde animal e ao ambiente e com custos mais acessíveis. Como alternativa, o caulim é uma substância inerte usada rotineiramente no preenchimento de fórmulas, não apresentando nenhuma restrição alimentar, ambiental e de baixo custo. Suas características (similares a outros marcadores) o credencia como possível marcador para estimativa do CMS de ruminantes.

Por tanto, essa revisão tem como objetivo descrever as características da substância caulim, a fim de se conhecer a substância e propor como opção de marcador externo de consumo de matéria seca e excreção fecal de bovinos de corte em sistema de pastejo.

\section{REVISÃO DE LITERATURA}

\section{MARCADORES de CONSUMO E/OU EXCREÇÃO FECAL}

Os marcadores tem sido bastante utilizados em trabalhos de nutrição e alimentação animal, principalmente quando não é possível obter dados de excreção fecal e/ou digestibilidade de forma direta, como no caso de animais a pasto.

Algumas propriedades permitem caracterizar determinadas substâncias como marcadores, como ser inerte, não ser tóxico, não ter função fisiológica, não ser metabolizado, poder ser processado com o alimento, ser recuperado totalmente a partir do trato gástrico intestinal (TGI), não influenciar a motilidade e secreções intestinais, não influenciar e não ser influenciado pela microbiota do TGI, possuir propriedades físicoquímicas que não interfiram nos processos digestivos, fluir de forma similar ao material marcado e apresentar um método analítico fácil, preciso e acurado (Owens \& Hanson, 1992; Fahey \& Jung, 1983).

Considerando então todas as características descritas acima, como um marcador ideal (Mayes et al., 1986). Assim, pesquisas têm sido realizadas com intuito de descobrir novas substâncias apresente todas esses atributos.

Apesar de bastante utilizado esse método, ainda apresenta falhas, principalmente em relação a recuperação da concentração substância por meio das fezes. Sendo que, na maioria das vezes essa recuperação é inferior a $100 \%$, resultando em superestimativas da excreção fecal (Berchielli et al., 2006).

Segundo Berchielli et al. (2006) as variações nas concentrações fecais dos marcadores podem estar associadas à frequência de administração aos animais e, em algumas situações é impraticável coletar fezes mais de duas vezes ao dia, assim, devido à baixa frequência de amostragem, as amostras podem não ser representativas.

Portanto, o conhecimento da recuperação fecal dos marcadores nas fezes representa uma ferramenta para avaliação do marcador e/ou uma forma de possibilitar seu uso em situações em que sua recuperação nas fezes é diferente de $100 \%$ (Tabela I).

De acordo com Zeoula et al. (2002) algumas equações podem ser utilizadas para a avaliação de recuperações fecais na matéria seca (MS), tais como:
Recuperação fecal da MS = (grama de MS fecal estimada) / (grama de MS fecal real) * 100;

Gramas de MS fecal estimada $=$ (grama ingerida do marcador) / (\% de marcador nas fezes);

Recuperação do marcador $=(1 /$ Recuperação de MS fecal) * 100 .

Existem dois tipos de marcadores capazes de predizerem as avaliações nutricionais de animais a pasto, internos e externos. Os internos são representados por alguns componentes intrínsecos à dieta e geralmente são mais utilizados em estimativas de digestibilidade aparente. Por outro lado, os externos são fornecidos ao animal via oral ou ruminal, representados por substâncias que não fazem parte da dieta.

Entre os representantes de marcadores internos incluem, a lignina. Essa substância é formada por polímeros condensados resistentes à hidrólise ácida e alcalina e à diversos complexos enzimáticos (Fukushima \& Hatfield, 2003), estas características indicam a indigestibilidade do marcador.

A característica de não ser digerida e a recuperação quantificável nas fezes incentivou o uso da lignina como marcador interno. Entretanto, existe a possibilidade desses polímeros serem degradados durante a passagem pelo TGI alterando sua recuperação nas fezes (Cavalcanti et al., 2013). Dessa forma, sua utilização como marcador torna-se questionável uma vez que foi demonstrada grande variação da digestibilidade da lignina (27,9 a 53,3\%) em diversas dietas (Fahey \&Jung, 1983).

Recomenda-se utilizar a lignina como marcador quando sua concentração na MS das rações for superior a $5 \%$, porém deve-se ter cautela ao utilizá-la devido sua incompleta recuperação fecal que resultará em subestimativa da digestibilidade (Cavalcanti et al., 2013).

Os pigmentos de plantas completamente recuperados nas fezes são chamados de cromogênios. Seu uso como marcador interno limita-se à forragem com grande conteúdo de clorofila (Burns et al., 1994). Por esse motivo apresenta baixa frequência de utilização, além dos resultados muito variáveis e pouco confiáveis (Cavalcanti et al., 2013).

A sílica também usada como marcador interno, apresenta uso limitado pois, apesar de ser indigestível e recuperada nas fezes, sua concentração nas forragens é considerada inconsistente devido à grande ocorrência de contaminação pelo solo (Burns et al., 1994).

As cinzas, insolúvel em ácido (CIA) e em detergente ácido (CIDA), também constituintes naturais da dieta, apresentam estimativas satisfatórias (Cavalcanti et al., 2013)

As vantagens do seu uso como marcador interno tem como bases suas análises simples e rápidas e ausência de variações diurnas e diárias dos marcadores (Araújo et al., 2000; Zeoula et al., 2002).

Para que a predição da digestibilidade a partir desses marcadores seja acurada os resultados de estimativa da recuperação fecal devem ser confiáveis, para 


\begin{tabular}{|c|c|c|c|c|}
\hline Marcador & $\mathrm{RF}^{1}(\%)$ & Acurácia ${ }^{2}$ & Precisão ${ }^{3}$ & Referência \\
\hline \multirow[t]{4}{*}{ Lignina em detergente ácido } & 110,50 & & & Bohnert et al., 2000 \\
\hline & 89,60 & & & Pombo et al., 2016 \\
\hline & 74,40 & $-10,60$ & 3,72 & Rodrigues et al.,2010 \\
\hline & 100,00 & $-0,56$ & 7,02 & Siqueira et al., 2009 \\
\hline \multirow[t]{7}{*}{ Fibra em detergente ácido indigestível } & 99,90 & & & Bohnert et al., 2000 \\
\hline & 89,76 & & & Zeoula et al., 2002 \\
\hline & 103,67 & & & Oliveira et al., 2012b \\
\hline & 99,40 & & & Pombo et al., 2016 \\
\hline & 130,00 & & & Cezimbra, 2010 \\
\hline & 93,70 & $-2,47$ & 3,24 & Rodrigues et al.,2010 \\
\hline & 102,07 & & & Sampaio et al., $2011^{a}$ \\
\hline \multirow[t]{6}{*}{ Fibra em detergente neutro indigestível } & 101,60 & & & Zeoula et al., 2002 \\
\hline & 107,00 & & & Cezimbra, 2010 \\
\hline & 94,08 & & & Oliveira et al., 2012b \\
\hline & 96,00 & & & Pombo et al., 2016 \\
\hline & 90,90 & $-3,50$ & 3,67 & Rodrigues et al.,2010 \\
\hline & 98,87 & & & Sampaio et al., 2011a \\
\hline Cinza insolúvel em ácido & 105,77 & & & Zeoula et al., 2002 \\
\hline \multirow[t]{2}{*}{ Dióxido de titânio } & 174,00 & & & Cezimbra, 2010 \\
\hline & 101,95 & & & Sampaio et al., 2011a \\
\hline \multirow[t]{2}{*}{ LIPE $^{\circledR}$} & 86,00 & & & Cezimbra, 2010 \\
\hline & 95,94 & & & Lanzetta et al., 2009 \\
\hline \multirow[t]{4}{*}{ Óxido crômico } & 86,10 & $-4,62$ & 1,24 & Rodrigues et al.,2010 \\
\hline & 99,50 & & & Sampaio et al., 2011 \\
\hline & 88,00 & $-4,69$ & 3,14 & Siqueira et al., 2009 \\
\hline & 83,73 & & & Lanzetta et al., 2009 \\
\hline
\end{tabular}

\footnotetext{
${ }^{1}$ RF: Recuperação fecal dos indicadores; ${ }^{2}$ Acurácia dos marcadores avaliada pelo viés médio; ${ }^{3}$ Precisão dos marcadores avaliada pela
} raiz quadrada média do erro de predição (RQMEP).

isso, recomenda-se utilizar alimentos que contenham concentração mínima de $0,75 \%$ de CIA e concentração superior a 3\% de CIDA na MS (Thonney et al., 1984;Berchielli et al., 2000).

Deve-se ter cuidado quanto ao risco de ingestão de solos, quando utilizados em experimento com animais sob pastejo, pois essa ingestão representa importante fonte de erro na determinação da digestibilidade (Cavalcanti et al., 2013).

Os marcadores representados pelos resíduos indigestíveis (MSi, FDNi e FDAi) precisam ser submetidos à digestão, permanecendo no rúmen por período mínimo de 144 horas pela técnica de incubação in situ (Berchielli et al., 2000). Existe grande falta de padronização nos estudos de resíduos indigestíveis, incluindo diferenças nos tempos de incubação, entre tamanhos de partículas, porosidade dos sacos de incubação e quantidade de amostra, o que levou Rebouças et al. (2013) a proporem o uso de uma única metodologia nestes estudos como forma de padronização da técnica e possibilidade de comparação dos resultados.
A possibilidade de uso dos resíduos indigestíveis como marcadores internos está diretamente associada à semelhança estatística com os resultados obtidos por meio de coleta total.

O uso da MSi como marcador somente será possível caso seus valores de recuperação fecal sejam considerados nos cálculos, devido à alta variabilidade $(64,8$ a $108,4 \%$ ) (Kozloski et al., 2009). Ainda assim, a técnica mostra-se pouco precisa para detectar pequenas diferenças na digestibilidade, devido seu baixo coeficiente de determinação (63\%) (Kozloski et al., 2009).

Maior variabilidade e menor precisão na recuperação fecal da MSi em comparação à FDNi foi demonstrado por Sampaio et al. (2011a). Isto pode estar associado a falta de constância da contaminação microbiana entre os materiais (Casali et al. 2008) e ausência de homogeneidade entre as repetições. Porém, o uso da MSi foi considerado mais aceitável quando comparado à FDNi (Kozloski et al., 2009).

As altas concentrações de FDNi na MS da dieta $(15,31$ e 17,88\%) (Berchielli et al., 2000) são indicativos de resultados satisfatórios nas estimativas de digestibi- 
lidade. Entretanto, a técnica de FDNi mostrou-se pouco precisa quando comparada aos dados observados, apresentando baixo coeficiente de determinação (60\%) e recuperação altamente variável e incompleta $(49,5$ a 67,9\%) (Kozloski et al., 2009).

Assim como a FDNi, ao utilizar a FDAi como marcador interno, deve-se considerar a composição da fibra, o tamanho das partículas incubadas, o número de dias e horários de coletas de fezes e o tempo de incubação ruminal (Zeoula et al., 2002).

Os dados observados em alguns trabalhos vêm demonstrando inconstâncias nos resultados obtidos a partir do uso de FDNi como marcador, a exemplo temse dados de digestibilidade subestimados (Zeoula et al., 2000), recuperação fecal da FDNi próxima de $100 \%$ (Zeoula et al., 2002) e subestimativas da produção fecal (Ítavo, 2001).

Ao escolher a FDAi como marcador maior cuidado analítico deve ser tomado, especialmente durante as pesagens, pois apresenta pequena massa residual ficando sujeito a maiores erros de acurácia (Sampaio et al., 2011a). Contudo, estudos encontraram resultados de digestibilidade, estimados a partir da FDAi, estatisticamente iguais aos obtidos por coleta total de fezes (Berchielli et al., 2000), e existe a recomendação de escolha do marcador FDAi para estimativas de produção fecal em detrimento do FDNi pelo fato deste último resultar em subestimativas (Ítavo, 2001).

Os n-alcanos de cadeia ímpar são componentes naturais da cera cuticular formados por cadeias ímpares de 25 a 35 átomos de carbono $\left(C_{25}\right.$ a $C_{35}$ ) (Cavalcanti et al., 2013). Foram considerados adequados como marcadores fecais indigestíveis pelo fato de serem quimicamente inertes e por serem mais facilmente analisados quando comparados aos ácidos graxos de cadeia longa que haviam sido considerados como possíveis marcadores (Mayes et al., 1984).

Para obter estimativas acuradas recomenda-se que a concentração de alcanos naturais nas plantas seja superior a $50 \mathrm{mg} / \mathrm{kg}$ de MS (Casson et al., 1990). Contudo, a técnica apresenta limitações, como a necessidade de conhecimento prévio do perfil de n-alcanos da forragem consumida pelo animal (Côrtes et al., 2005), a variação da concentração dos alcanos entre as forrageiras e também dentro da mesma espécie de acordo com o período do ano ou ciclo vegetativo (Cavalcanti et al., 2013).

Outras substâncias de grande importância para os estudos de consumo e digestibilidade são os marcadores externos. Essas substâncias podem ser administradas em dose única ou continuamente, com determinada frequência em um período de tempo, objetivando alcançar um equilíbrio de forma que a digesta esteja marcada uniformemente e a taxa de saída seja constante (Marais, 2000).

A administração individual diária do marcador exige que os animais em pastejo sejam deslocados do piquete ao curral, contidos no tronco e que sejam submetidos à introdução oral de cápsulas contendo a quantidade exata do marcador, com auxílio de sonda esofágica. Tal procedimento provoca mudanças com- portamentais de pastejo, causa estresse nos animais acostumados a permanecerem constantemente no piquete, além de poderem provocar irritações na mucosa oral e do esôfago.

Existem substâncias administradas aos animais que apresentam liberação controlada do marcador (bólus). Estas apresentam a vantagem de não necessitar da administração diária do marcador, contudo é comum ocorrer estimativas superiores da produção fecal devido à discordância entre a taxa de liberação descrita no equipamento (utilizada nos cálculos) e a verdadeira taxa de liberação (Marais, 2000).

$\mathrm{O}$ marcador externo dióxido de titânio $\left(\mathrm{TiO}_{2}\right)$ é insolúvel em água, de coloração branca, sem odor ou sabor (Cavalcanti et al., 2013). Este pode ser utilizado como substituto do óxido crômico, pois apresenta completa recuperação fecal, com valores iguais estatisticamente a 100\% $(99,51$ e 104\%), não é afetado pelas diferentes condições de alimentação e não apresenta limitação quanto a sua inclusão na dieta animal (Sampaio et al., 2011a). Apresenta como vantagem a inexistência de propriedades carcinogênicas (Cavalcanti et al., 2013).

O dióxido de titânio não tem efeito prejudicial sobre ovinos quando ingerido 2 a 3 g por dia, apresentando recuperação fecal de 98\% (Marais, 2000). Em estudos com novilhos, Titgemeyer et al. (2001) também indicaram a possibilidade de uso desta substância para bovinos. Uma das principais limitações encontra-se na escolha da técnica para determinação do marcador que deve apresentar resultados quantitativos precisos e não apenas qualitativos (Cavalcanti et al., 2013).

Os lantanídeos são representados por quinze elementos químicos que compõe o grupo de metais terras-raras, sendo que diversos deles são utilizados como marcadores, como o itérbio, lantânio, cério, disprósio e európio (Marais, 2000).

Dentre os lantanídeos, o elemento mais utilizado como marcador externo é o cloreto de itérbio (Silva \& Costa, 2013), que apresenta concentração constante em 24 horas de amostragem (Owens \& Hanson, 1992). O itérbio tende a se dissociar da partícula de alimento e migrar para partículas não marcadas, além da possibilidade de sofrer solubilização em meios ácidos como o abomaso (Crooker et al., 1982). Ao comparar os coeficientes de digestibilidade obtidos a partir do cloreto de itérbio e coleta total, Saliba et al. (2002) observaram que o marcador externo subestimou os resultados em $24 \%$.

Os N-alcanos de cadeia par, com 28 a 32 carbonos $\left(\mathrm{C}_{28}\right.$ a $\left.\mathrm{C}_{32}\right)$, são utilizados como marcadores externos, pois ocorrem em concentração muito baixa nas plantas (<40 mg/kg de MS) (Cavalcanti et al., 2013).

A recuperação fecal desses marcadores varia de 78,8 a $88,9 \%$ entre os n-alcanos de menor $\left(C_{28}\right)$ e maior $\left(C_{32}\right)$ cadeia, respectivamente, e essas variações nas taxas de recuperação se assemelham entre os n-alcanos de cadeia ímpar $\left(\mathrm{C}_{25}\right.$ a $\left.\mathrm{C}_{35}\right)$ (Mayes et al., 1986).

A combinação de n-alcanos de cadeia par e ímpar em uma mesma dieta pode ser utilizada como ferramenta para estimativa de consumo de MS. Nestes 
casos, o cálculo do consumo diário de MS pelo método do duplo n-alcano é determinada pela equação: Consu$\mathrm{mo}(\mathrm{kg} \mathrm{MS} / \mathrm{dia})=\left[(\mathrm{Fi} / \mathrm{Fp}){ }^{*} \mathrm{Ddp}\right] /\left[\mathrm{Hi}-\left(\mathrm{Fp}{ }^{*} \mathrm{HP}\right)\right]$, onde: Fi e Fp representam respectivamente, os teores de $\mathrm{n}$-alcanos de cadeia ímpar e par nas fezes $(\mathrm{mg} / \mathrm{kg}$ MS); Hi e Hp são respectivamente, os teores de n-alcanos de cadeia ímpar e par nas forragens (mg/kg MS); Ddp é a dose diária de n-alcanos de cadeia par (mg/ kg MS) (Cavalcanti et al., 2013).

Alguns aspectos dos n-alcanos limitam sua escolha como marcador nos estudos de consumo e digestibilidade, como o alto custo (Carvalho et al., 2007), a necessidade de conhecimento prévio do perfil de n-alcanos da forragem consumida pelo animal (Côrtes et al., 2005), a ocorrência de variações importantes na concentração fecal quando administrado uma vez ao dia (Berchielli et al., 2006) e, quando se utiliza a técnica do duplo n-alcano, a ocorrência de baixas concentrações em determinadas gramíneas tropicais (Laredo et al., 1991).

Conhecido como sesquióxido de cromo, o óxido crômico é um dos marcadores externos mais difundidos e utilizados nas estimativas de produção fecal. As vantagens apresentadas por este marcador como, ser facilmente incorporado à dieta, apresentar análise relativamente fácil e baixo custo em relação aos demais (Morenz et al., 2006), além de permitir estimativas satisfatórias do consumo de MS de bovinos a pasto (Oliveira et al., 2004) são alguns dos motivos para a escolha do óxido crômico como marcador externo nos estudos de consumo.

Algumas desvantagens relacionadas ao uso desse marcador foram relatadas na literatura, incluindo a incompleta homogeneização na dieta (Coelho Silva \& Leão, 1979), alta variação diurna de excreção fecal (Owens \& Hanson,1992; Van Soest, 1994; Kozloski et al., 2006), recuperação incompleta (Mir et al., 1989), passagem mais rápida pelo rúmen que o material fibroso e possibilidade de acúmulo em partes do TGI (Van Soest, 1994), além do potencial carcinogênico que tem limitado seu uso, havendo gradual substituição por outros marcadores (Oliveira et al., 2012a).

Ao comparar a produção fecal estimada a partir do marcador óxido crômico com a produção real, Barros et al. (2009), demonstraram uma estimativa superior da produção fecal em 5\%, com boa recuperação do marcador (96,92\%). Da mesma forma, Soares et al. (2004), em estudo do consumo de MS utilizando a técnica do óxido crômico encontraram resultados superestimados em $9,25 \%$ do consumo.

Pesquisas sobre lignina isolada de resíduos de milho por Saliba et al. (1999) deram início aos estudos sobre o marcador externo LIPE ${ }^{\circledR}$, caracterizado como hidroxifenilpropano modificado e enriquecido, marcador externo desenvolvido especificamente para pesquisa (Saliba, 2013).

Os resultados apresentados por Oliveira (2005) demonstraram que a excreção fecal e o consumo obtidos por meio desse marcador não diferem daqueles obtidos pelo óxido crômico o que caracteriza o LIPE $^{\circledR}$ como um marcador externo capaz de estimar satisfatoriamente a excreção fecal e o consumo de bovinos. Da mesma forma, Soares et al. (2011) indicaram o LIPE ${ }^{\circledR}$ como marcador externo de estimativas acuradas para a produção fecal de búfalos pelo fato dos resultados não diferirem dos valores do total de produção fecal.

A utilização do LIPE $^{\circledR}$ permite obter estimativas acuradas e eficientes de produção fecal em experimentos com diversas espécies animais, realizando análises rápidas e simples por meio de espectroscopia de infravermelho próximo (Saliba et al., 2015). Porém, por se tratar de uma técnica desenvolvida especificamente para pesquisa (Saliba, 2013), seu uso limita-se aos experimentos e meio acadêmico.

Assim, a determinação do consumo, digestibilidade e excreção fecal de bovinos de corte, realizada por técnicas indiretas está intimamente relacionada com a escolha do marcador que representa um importante passo para resultados acurados e precisos. $\mathrm{O}$ fato de todos os marcadores em uso apresentarem limitações abre espaço para a busca de novas substâncias ou moléculas que apresentem propriedades favoráveis como futuros marcadores. O caulim destaca-se como interessante alternativa, pois já faz parte da nutrição dos animais e por se tratar de um mineral cujas características evidenciam possível aplicação como marcador fecal.

\section{Caulim}

O termo caulim é derivado de uma localidade conhecida como Kao-Ling na China, que significa colina alta, onde a população local utilizava a argila presente no solo da colina na produção de porcelanas finas, sendo esta a razão de ser comercialmente conhecido como "China Clay" (Bristow, 1987b).

O caulim é um argilomineral representado principalmente pela caulinita e haloisita, presentes em abundância na natureza (Silva, 2001). Apresenta várias aplicações industriais (Murray, 2000; 2007), bastante utilizado como material de enchimento (Xiang and $\mathrm{Gu}, 2006$; Rugmini and Menon, 2008), como pigmentos para papel (Murray and Kogel, 2005; Vimonses et al., 2009), e também é muito utilizado na indústria de ração animal (Bordonalli, 1995).

A rocha de caulim é composta principalmente de minerais do grupo caulinita, e componentes como o quartzo, mica, feldspato, óxidos de ferro (Fe), alumínio (Al) e titânio (Ti) (Luz \& Damasceno, 1993).

A variabilidade dos elementos minerais que originam o caulim ocorre devido a variação dos tipos de rochas envolvidas em sua formação, sendo observado diferentes grupos de caulins nos principais depósitos do Brasil (Figura 1).

A alteração das rochas feldspáticas por processo geológico resultam na formação do caulim, ocorrendo dois tipos de depósitos: a) primários ou residuais, resultante da alteração de rocha por processo de intemperismo, hidrotermal ou "solfatara"; b) secundário, formado pela deposição de materiais transportados por correntes de água doce, sendo estes classificados como sedimentares, areias cauliníticas e argilas plásticas (Luz \& Damasceno, 1993; Luz et al., 2009). 


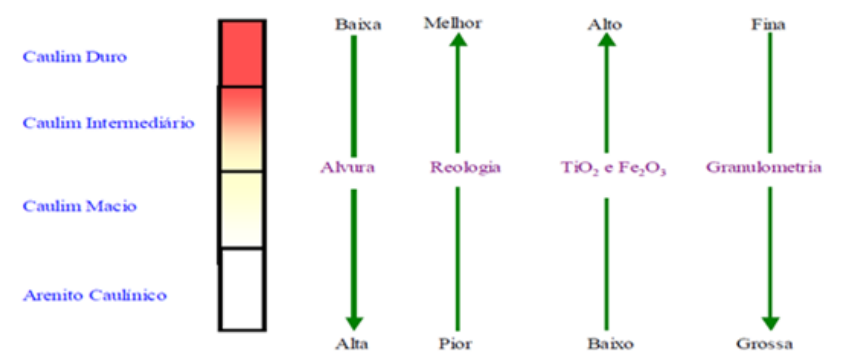

Figura 1. Diferentes grupos de caulins nos principais depósitos do Brasil (Different groups of kaolins in the main deposits in Brazil).

A formação do caulim por intemperismo se dá pela ação climática quente e úmida principalmente sobre granitos, gnaisses e meta-arcósios, com geração de depósitos irregulares tanto na forma como na espessura (Bordonalli, 1995).

A caulinização da rocha ocorre devido à hidratação de um silicato anidro de alumínio, seguida da remoção de álcalis, conforme reação a seguir (Luz et al., 2009).

$\mathrm{O}$ processo de hidrotermalismo ocorre com a passagem de fluidos hidrotermais em falhas e fraturas do corpo rochoso e posterior ação de águas superficiais e de baixas temperaturas que completam a caulinização dos feldspatos (Witte, 1993).

A alteração tipo "solfatara" ocorre a partir da ação vulcânica ácida, constituídas de vapores e águas quentes, ricos em enxofre, que passam entre as rochas formando o caulim (Bristow, 1987a). Estes tipos de depósitos são pouco encontrados no Brasil devido às características geológicas da região, onde não existem relatos de atividade vulcânica. Neste caulim, o quartzo ocorre em granulometria fina, semelhante da caulinita, sendo difícil sua remoção, portanto torna-se um produto abrasivo (Luz et al., 2009).

Os depósitos primários de caulim encontrados no Brasil resultam da alteração intempérica de rochas cristalinas, e os secundários são resultados do processo de sedimentação dos depósitos primários (Luz \& Damasceno, 1993).

As diferentes origens geológicas dos caulins secundários resultam em diferenças na composição mineralógica (Luz et al., 2009), em geral com maior concentração de contaminantes como óxido de ferro (Fe) e titânio (Ti) (Bristow, 1987a, Luz e Damasceno, 1993), porém sua granulometria é a mais fina dos argilominerais (Luz et al., 2009).

Os caulins secundários são classificados em três grupos: sedimentares, areias cauliníticas e argilas plásticas, refratárias e silicosas (Luz e Damasceno, 1993). E, apresenta-se elevada porcentagem de caulinita após seu beneficiamento, enquanto as areias cauliníticas contêm menos de $20 \%$ de caulinita (Luz et al., 2009).

As argilas plásticas (ball clays) são constituídas de caulinita, ilita e material carbonoso, sendo que as argilas refratárias apresentam composição química semelhante porém, ocorrem associadas a gibbsita e a haloisita (Luz et al., 2009). Enquanto as argilas silicosas (flint clays), segundo os mesmos autores, são constituídas de caulinita, contendo Fe e outros componentes escorificantes.

A caulinita é um dos minerais mais abundantes na crosta terrestre e, apresenta caráter hidrofílico ou lipofóbico que é conferido pelo fato da superfície de seus cristais ser formada por ânions de um lado $\mathrm{OH}^{-}$e de outro $\mathrm{O}^{2-}$ (Coelho et al., 2007).

O grupo das caulinitas é subdividido de acordo com a presença e a natureza de seus constituintes e dos demais minerais associados (Bordonalli, 1995). São quatro as argilas básicas desse grupo: o caulim, que é nosso objeto de estudo, o "ball clay", as argilas refratárias e a haloisita (Santos, 1975).

A haloisita, mineral do grupo das caulinitas também abundante no caulim, difere deste por apresentar forma tubular e viscosidade seis a sete vezes maior (Bordonalli, 1995).

Os caulins são aluminossilicatos hidratados, cuja composição aproxima-se de $\mathrm{Al}_{2} \mathrm{Si}_{2} \mathrm{O}_{5}(\mathrm{OH})_{4}$, o que corresponde a aproximadamente $46,5 \%$ de $\mathrm{SiO}_{2}, 39,5 \%$ de $\mathrm{Al}_{2} \mathrm{O} 3$ e $14 \%$ de $\mathrm{H}_{2} \mathrm{O}$ e outros elementos em menor quantidade como $\mathrm{Fe}$, Ti, manganês (Mn), magnésio $(\mathrm{Mg})$, potássio (K) e sódio (Na) (Giese Jr., 1988), estes últimos representam as impurezas do caulim (Bordonalli, 1995).

A coloração branca do caulim é um dos principais fatores responsáveis por seu grande uso industrial e está associada com a característica da caulinita que apresenta íons incolores e quando esses cristais se encontram na forma de pó apresentam cor branca (Coelho et al., 2007). A composição química e mineralógica dos caulins varia de acordo com o tipo de depósitos e localização no Brasil (Tabela II).

Independentemente do tipo de formação (primária ou secundária), a qualidade do caulim dependerá de alguns padrões físicos e químicos, como a alvura, distribuição granulométrica, viscosidade, porcentagem de areia e de óxidos de Al e silício (Si) (Bordonalli, 1995).

Existe grande variedade de produtos no mercado, incluindo caulins beneficiados e não beneficiados (Bordonalli, 1995). O produto não beneficiado trata-se do caulim extraído e imediatamente consumido (minério ou caulim bruto), sem que haja tratamento químico ou magnético posterior à extração (Bordonalli, 1995). Enquanto o caulim beneficiado, de carga ou cobertura, pode ser obtido por beneficiamento a seco ou úmido, e tem o objetivo de realçar determinadas propriedades do caulim, como alvura, granulometria, viscosidade e superfície específica (Bordonalli, 1995).

O beneficiamento a seco é realizado quando o caulim apresenta alvura, distribuição granulométrica adequada e baixo teor de quartzo (Luz et al., 2009). O processo consiste em fragmentar o caulim bruto (rocha), secar em secadores rotativos e pulverizar em moinhos de rolo e, por último separar partículas por flotação de ar, onde as partículas mais finas são conduzidas para o topo do aero separador por uma corrente de ar quente (Luz et al., 2009). 


\begin{tabular}{|c|c|c|c|c|c|c|c|c|c|c|c|c|c|c|}
\hline \multirow{2}{*}{$\begin{array}{l}\text { Tipo de } \\
\text { depósito }\end{array}$} & \multirow[b]{2}{*}{$\mathrm{M}^{1}{ }^{1}$} & \multirow[b]{2}{*}{ Localização } & \multicolumn{8}{|c|}{ Análise Química (Peso \% FRX)² } & \multicolumn{4}{|c|}{ Análise mineralógica (Peso \% DRX)2 } \\
\hline & & & $\mathrm{SiO}_{2}$ & $\mathrm{Al}_{2} \mathrm{O}_{3}$ & $\mathrm{Fe}_{2} \mathrm{O} 3$ & $\mathrm{CaO}$ & $\mathrm{MgO}$ & K2O & $\mathrm{NaO}$ & LOI & Caulim & Mica & Feldspato & Quartzo \\
\hline \multirow[t]{3}{*}{ Sedimentar } & $\mathrm{L}$ & Tio Jari, PA & 45 & 37 & 2,2 & 0,03 & 0,03 & 0,01 & 0,08 & 14,4 & 99 & $\operatorname{tr}$ & - & $\operatorname{tr}$ \\
\hline & $\mathrm{L}$ & Plateau Berenice & 45 & 38 & 2,1 & 0,04 & 0,01 & 0,01 & 0,07 & 14 & 99 & $\operatorname{tr}$ & - & $\operatorname{tr}$ \\
\hline & $\mathrm{T}$ & Registro, SP & 47 & 37 & 0,8 & 0,05 & 0,06 & 0,04 & 0,11 & 14,5 & 93 & 5 & - & - \\
\hline \multirow[t]{5}{*}{ Pegmatitos } & $\mathrm{T}$ & Marilac, MG & 46 & 40 & 0,05 & 0,04 & 0,03 & 0,53 & 0,05 & 13,8 & 95 & 4 & $\operatorname{tr}$ & $\operatorname{tr}$ \\
\hline & $\mathrm{T}$ & Bicas, MG & 46 & 40 & 0,06 & 0,03 & 0,08 & 0,24 & 0,06 & 13,8 & 95 & 4 & - & - \\
\hline & $\mathrm{T}$ & S. Antonio, Rio & 46 & 39 & 0,26 & 0,08 & 0,26 & 0,84 & 0,29 & 13,1 & 95 & 4 & - & $\operatorname{tr}$ \\
\hline & $\mathrm{T}$ & Conceição, MG & 46 & 39 & 0,05 & 0,03 & 0,05 & 0,21 & 0,12 & 14 & 94 & 6 & - & - \\
\hline & $\mathrm{L}$ & Junco, PB & 46 & 39 & 0,26 & 0,05 & 0,11 & 0,54 & 0,08 & 13,7 & 93 & 6 & - & 1 \\
\hline \multirow[t]{3}{*}{ Graníticos } & $\mathrm{L}$ & Jundiapeba, SP & 46 & 39 & 0,71 & 0,04 & 0,12 & 1,25 & 0,12 & 13 & 90 & 7 & - & 1 \\
\hline & $\mathrm{T}$ & Embu, SP & 46 & 39 & 0,36 & 0,07 & 0,09 & 0,74 & 0,43 & 13,6 & 96 & 4 & - & - \\
\hline & $\mathrm{T}$ & Piracicaia, SP & 49 & 35 & 1,4 & 0,05 & 0,16 & 2,4 & 0,8 & 12,1 & 82 & 7 & 9 & 2 \\
\hline Anortosito & $\mathrm{T}$ & Encruzilhada, RS & 45 & 40 & 0,34 & 0,24 & 0,44 & 1,1 & 0,18 & 13,1 & 85 & 15 & - & $\operatorname{tr}$ \\
\hline \multirow[t]{2}{*}{ Vulcânico } & $\mathrm{T}$ & $\begin{array}{c}\text { S. Beto (Turvo), } \\
\text { SC }\end{array}$ & 52 & 34 & 0,53 & 0,05 & 0,21 & 0,28 & 0,07 & 12,1 & 93 & - & - & 7 \\
\hline & $\mathrm{T}$ & S. Beto (Kovalski) & 57 & 30 & 0,98 & 0,05 & 0,26 & 1,9 & 0,06 & 11,1 & 89 & - & - & 11 \\
\hline
\end{tabular}

${ }^{1} \mathrm{M}=$ Morfologia $-\mathrm{L}=$ Caulinita laminar; $\mathrm{T}=$ Haloisita tubular; ${ }^{2} \mathrm{FRX}=$ Fluorescência de raio $\mathrm{X}$ (Peso \%); DRX = Difração de raio $\mathrm{X}($ Peso $\%) ; \operatorname{tr}=$ traço

As etapas envolvidas no beneficiamento a úmido são dispersão, desareamento, fracionamento em hidrociclone ou centrífuga, separação magnética, floculação seletiva, alvejamento químico, filtragem e secagem (Monte et al., 2001) (Figura 2).

Parâmetros como a variedade do caulim produzido, a tipologia dos depósitos, os tipos de produtos e formas de beneficiamento permitem a divisão qualitativa do caulim em caulim de alto padrão, de padrão intermediário e padrão marginal (Bordonalli, 1995).

O caulim de alto padrão ou "coating" apresenta alvura elevada (85-91\%) e 78 a $98 \%$ das partículas apresentam granulometria inferior a $2 \mu \mathrm{m}$ (Bordonalli, 1995). Diferentemente, o caulim de carga apresenta qualidade inferior com alvura variando entre 70 e $80 \%$ e granulometria abaixo de $2 \mu \mathrm{m}$ representados por 30 a $97 \%$ do material (Bordonalli, 1995).

O padrão marginal confere ao caulim um perfil para ser utilizado em cerâmica, cimento branco e ração animal, o mesmo pode ser comercializado na forma beneficiada a seco, úmido ou na forma bruta (Bordonalli, 1995). Existe uma diferenciação do caulim de acordo com a granulometria e quantidade de quartzo, em caulim duro, intermediário, macio e arenito caulínico (Figura 3) (Criscuolo, 2008).

O caulim apresenta algumas características que o credenciam como potencial marcador externo em estudos de consumo e digestibilidade, como ser inerte em ampla faixa de pH (3 a 9), fácil dispersão, baixa condutividade térmica e elétrica, pouca abrasividade, baixo custo (Silva, 2007; Luz et al., 2009) e boa resis- tência ao ataque químico por ácidos ou álcalis (Coelho et al., 2007).

Outra característica atrativa desta substância para os estudos de consumo e digestibilidade está na facilidade de sua aquisição, pois o Brasil encontra-se em $5^{\circ}$ lugar no ranking mundial de produtores (Soeiro, 2014).

Os minerais argilosos, como a caulinita, podem ser utilizados no tratamento de algumas enfermidades, como situações patológicas crônica ou aguda de diarreia (Carretero, 2002). As características de adsorção e ausência de toxicidade primária do caulim (Anonymous, 1998) possibilitam considerá-lo material efetivo na prevenção de efeitos tóxicos causados no ambiente e/ou em organismos vivos por diversos materiais ( $\mathrm{Tr}-$ ckova et al., 2009).

A administração dietética de caulim resulta na redução da absorção de toxinas presentes na alimentação através da mucosa intestinal, uma vez que ele se liga seletiva e firmemente à substância toxica, eliminando seus efeitos (Trckova et al., 2009). Contudo, existe o risco de contaminação do caulim por micobactéria potencialmente patogênico, durante seu beneficiamento (Matlova et al., 2004).

Estudos demonstram que as argilas minerais podem aumentar o ganho de peso corporal e melhorar a conversão alimentar dos animais (Papaioannou et al., 2005; Alexopoulos et al., 2007; Trckova et al., 2009). Para alcançar esses resultados recomenda-se uma suplementação de dieta com 1 a 3\% de argilas adsorventes (Trckova et al., 2009). 
O efeito adsorvente sobre a eficiência animal é explicado pela redução da velocidade de passagem do alimento no intestino, melhorando a conversão e aumentando a reabsorção de água (Castro and Elias, 1978; Papaioannou et al., 2005). Outro mecanismo aceito por alguns autores é a melhora do crescimento e eficiência devido a redução da produção de amônia nos intestinos (Papaioannou et al., 2005).

\section{Determinação do Caulim nas fezes}

O caulim por ser um composto instável em meio ácido, pode dissociar-se no trago gástrico intestinal, como também reagir com outras substâncias orgânicas ou minerais do meio. Desta forma, não é possível sua identificação nas fezes, a não ser de forma indireta por meio de seus principais componentes - entre eles o silício ( $\mathrm{Si})$ e/ ou alumínio $(\mathrm{Al})$.

Entretanto para se saber qual o melhor elemento para se quantificar a substância caulim nas fezes, faz-se necessário o conhecimento da forma de excreção dos elementos (Si e Al), nível de absorção e tipos de contaminantes possíveis.

$\mathrm{O}$ silício, depois do $\mathrm{O}_{2}$, é o elemento mais abundante da crosta terrestre e está entre os doze elementos principais na composição dos organismos vivos (Santos, 2009). Enquanto o óxido de silício (SiO2) é o mineral mais abundante nos solos, constituindo a base da estrutura da maioria dos argilominerais (Barbosa Filho et al., 2001).

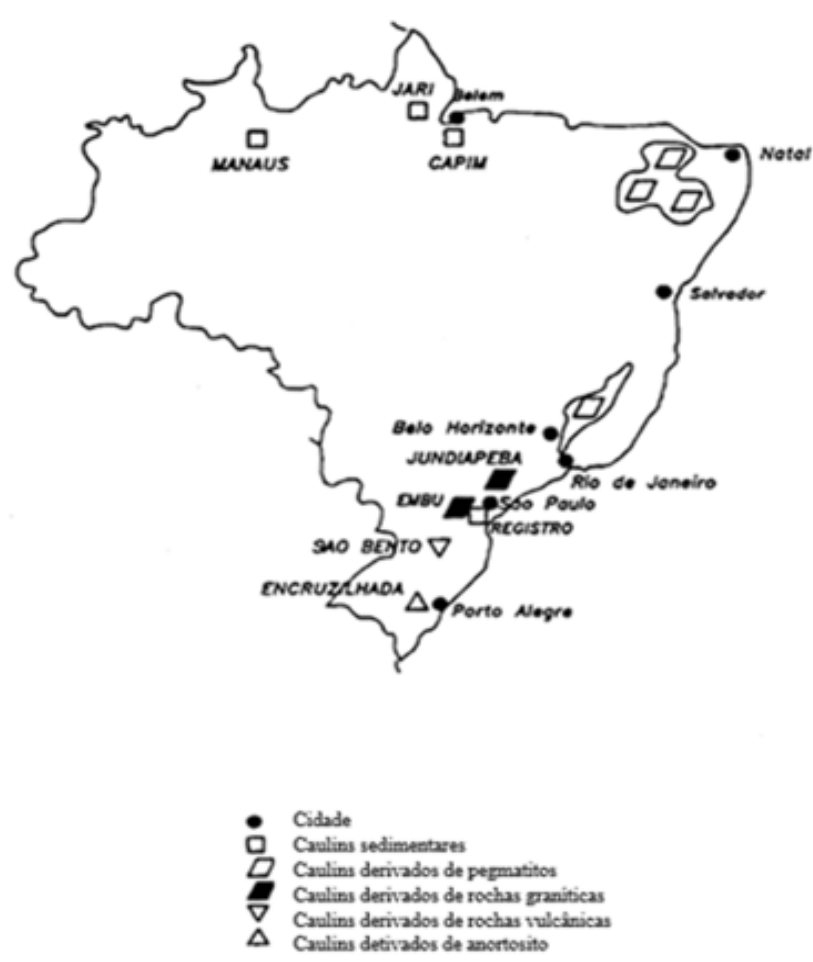

Figura 2. As etapas envolvidas no beneficiamento a úmido são dispersão, desareamento, fracionamento em hidrociclone ou centrífuga, separação magnética, floculação seletiva, alvejamento químico, filtragem e secagem (Monte et al., 2001) (The steps involved in wet processing are dispersion, desanding, fractionation in a hydrocyclone or centrifuge, magnetic separation, selective flocculation, chemical bleaching, filtering and drying (Monte et al., 2001)).
Em razão do avançado grau de intemperização em que se encontram os solos tropicais, o Si é encontrado basicamente na forma de quartzo, opala $\left(\mathrm{SiO}_{2} \cdot \mathrm{nH}_{2} \mathrm{O}\right)$ e outras formas não- disponíveis às plantas (Barbosa Filho et al., 2001).

A adubação com Si pode resultar em aumento na produtividade de várias culturas como o arroz e canade-açúcar (Anderson et al., 1991). Esses autores relacionam a presença do Si na planta com resistência à pragas e doenças, maior capacidade fotossintética (as folhas ficam mais eretas e a incidência de luz é maior) e tolerância à falta de água.

Mesmo não sendo considerado elemento essencial para o desenvolvimento das plantas, sua absorção pode trazer inúmeros benefícios, principalmente para culturas acumuladoras de Si, como o arroz (Mengel \& Kirkby, 1987). As plantas absorvem o Si da solução do solo na forma de ácido monossilícico $\mathrm{Si}(\mathrm{OH}) 4$, juntamente com a água e se acumula principalmente nas áreas de máxima transpiração (tricomas, espinhos) como ácido silícico polimerizado (sílica amorfa) (Tisdale et al.,1993).

Em geral, são consideradas plantas acumuladoras de $\mathrm{Si}$, aquelas que possuem teor foliar acima de $1 \%$, e não acumuladoras plantas com teor de silício menor que $0,5 \%$ (Ma et al., 2001).

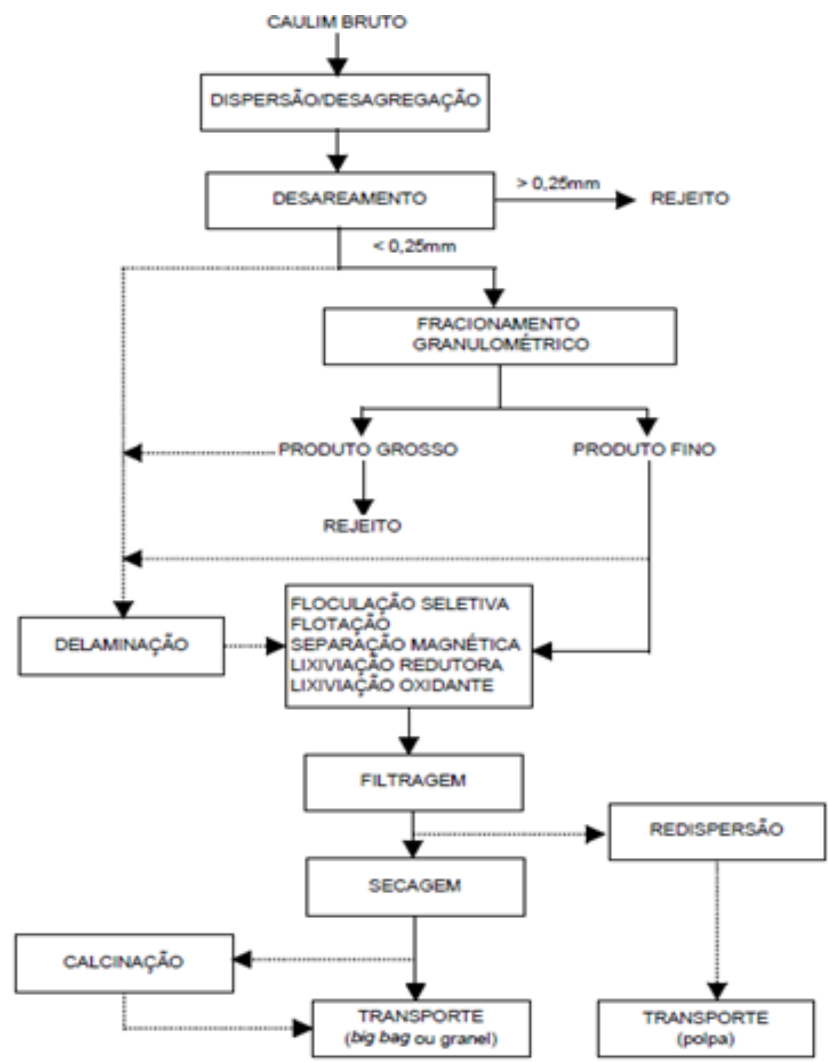

Figura 3. Diferenciação do caulim de acordo com a granulometria e quantidade de quartzo, em caulim duro, intermediário, macio e arenito caulínico (Criscuolo, 2008) (Differentiation of kaolin according to particle size and quantity of quartz, in hard, intermediate, soft kaolin and kaolin sandstone (Criscuolo, 2008)). 
O Si, ao ser absorvido pelas plantas, é facilmente translocado no xilema, e tem tendência natural a se polimerizar. Mais de $94 \%$ do $\mathrm{Si}$ absorvido pelo trigo é transportado rapidamente para a parte aérea, concentrando-se nas folhas mais velhas, com teores de até $11,8 \%$ de Si.

Na planta, o silício concentra-se nos tecidos de suporte, caule e folhas, podendo ser encontrado em pequenas quantidades nos grãos. Em geral, o conteúdo médio de silício das raízes é menor se comparado com o caule e folhas, em alguns casos, como a soja, o teor de Si na raiz é maior do que nas folhas (Oliveira, 2004).

Do ponto de vista técnico, determinações indiretas do caulim via $\mathrm{Si}$, apresentam como dificuldades as altas concentrações de Si contaminantes, oriundos de outras fontes, como solo e plantas (forragens), o que exige estratégias de separação e identificação destes.

A ingestão oral de silício por espécies monogástricas não representa risco à saúde, contudo, a ingestão de plantas ricas em Si pode resultar em cálculos renais silicosos em ruminantes (McDowell, 1992), além de reduzir a digestibilidade.

O silício é facilmente excretado pela urina, porém em algumas situações, como o consumo excessivo do mineral, pode ocorrer deposição do Si nos rins, bexiga ou uretra formando os cálculos ou urólitos (McDowell, 1992).

Já o elemento alumínio, é um componente do solo encontrado na natureza como minerais de argila, como caulinita, gibbsita e outros óxidos (Pedrotti et al. 2003). Não ocorre na natureza na forma elementar e, devido sua alta afinidade pelo oxigênio $(\mathrm{O})$ é encontrado na forma combinada $\mathrm{Al}^{3+}$, em rochas e minerais como, $\mathrm{Al}(\mathrm{OH}) 3, \mathrm{Al} 2 \mathrm{O} 3, \mathrm{Na}[\mathrm{Al}(\mathrm{OH}) 4], \mathrm{Al} 2(\mathrm{SO} 4) 3$ e haletos de alumínio (Constantino et al., 2002). O hidróxido de alumínio, composto químico de fórmula $\mathrm{Al}(\mathrm{OH}) 3$, é a forma mais estável de alumínio nas condições normais.

A caulinita é um mineral do grupo argilomineral, principal constituinte do caulim (Teixeira, 2015). Apresenta estrutura cristalina do tipo 1:1 o que lhe confere caráter hidrofílico ou lipofóbico (Coelho et al., 2007). A ligação de hidrogênio e o baixo grau de carga permanente conferem ausência de substituições isomórficas em sua estrutura, portanto existe baixa capacidade de troca cationica desse argilomineral (Khawmee et al., 2013)

Gibbsita tem uma típica estrutura de hidróxido metálico com ligações de hidrogênio, sendo constituída por duas camadas de grupos hidroxila com íons alumínio ocupando dois terços dos buracos octaédricos entre as duas camadas. Esse mineral é importante na agregação do solo devido sua característica microscópica, em que a estrutura tende a granular com o aumento dos seus teores no solo (Resende, 1985)

Alumínio é o terceiro elemento mais abundante na crosta terrestre, excedido apenas pelo O e Si (Pedrotti et al., 2003). Entretanto é encontrado apenas em quantidades traços nos organismos biológicos. Devido sua alta reatividade natural, o $\mathrm{Al}$ ocorre na natureza combinado com O, Si, Flúor (F) e outros compostos (McDowell,
1992), tornando-se insolúvel em condições ambientais, e desta forma, sua concentração em soluções aquosas e até mesmo nas fontes de suprimento para os animais é extremamente baixa (Miller et al., 1984).

$\mathrm{O} A \mathrm{Al}$ ao ser liberado dos minerais para a solução de solo pode causar problemas de fitotoxidez às plantas, reduzem a capacidade de troca catiônica do solo e influenciam atributos físicos do solo (Wada \& Harward, 1974; Goldberg, 1989). O sintoma mais visível de toxicidade de alumínio às plantas é a redução do crescimento do sistema radicular, causada por mecanismos diferentes, que atuam fora ou no interior das células (Delhaize, 1995).

Ocorre em alta variabilidade em plantas (McDowell, 1992), árvores e samambaias podem apresentar de 3000 a $4000 \mathrm{mg} / \mathrm{kg}$ de $\mathrm{Al}$ enquanto que em gramíneas e trevos os níveis não ultrapassam $50 \mathrm{mg} / \mathrm{kg}$ (Underwood, 1977). A constituição de Al nos solos fica entre 3 a $6 \%$, representado em sua maioria por complexos siliciosos insolúveis (Suttle, 2010).

Esses complexos insolúveis ocorrem predominantemente em solos com pH acima de 5,8 em que apresentam pequenas quantidades de Al trocável (McDowell, 1992), pois praticamente todo o mineral estará na forma insolúvel $\left(\mathrm{Al}(\mathrm{OH})_{3}\right)$, não tóxica para as plantas (Faquin, 2005). Sob essas condições de pH também apresentarão baixo potencial de toxidez aos animais em pastejo.

Em solos ácidos observa-se maior disponibilidade de Al trocável em solução de solo, que pode acarretar em toxicidade quanto maior for a absorção do elemento pelas plantas. Contudo, na intenção de se proteger do efeito tóxico do $\mathrm{Al}$, as plantas desenvolveram mecanismos de defesa durante seu processo evolutivo, como limitações da sua translocação para a parte aérea, procurando mantê-lo nas paredes celulares do córtex das raízes, na forma de compostos aluminossilicatos e complexação do $\mathrm{Al}$ em ácidos orgânicos nas raízes (Sangster et al. 2001; Ma, 2000).

A pastagem juntamente com o solo representa as principais fontes de $\mathrm{Al}$ para os animais, porém o pasto apresenta baixo teor de $\mathrm{Al}$, entretanto o solo é rico neste elemento. As partículas grosseiras ingeridas de solo provavelmente ficam retidas no retículo-rúmen, enquanto as partículas finas são rapidamente excretadas pelas fezes (Brebner et al., 1985). O alumínio pode constituir de 0,3 a $1,2 \%$ da matéria seca ingerida por animais em pastejo, pois, a ingestão de solo por estes animais pode representar 10 a $25 \%$ da ingestão de matéria seca (Healy et al., 1974; Thornton, 1974).

Existe a teoria que de que a maioria das formas de Al ingerida é gradualmente solubilizada pelo ácido clorídrico estomacal (Stewart, 1989; Lote \& Saunders, 1991), contudo, a solubilização gástrica dependerá da forma em que o Al ingerido se encontra (Powell \& Thompson, 1993). Os aluminossilicatos são pouco solúveis mesmo em pH ácido, e quando solubilizados não são absorvidos (Mauras et al., 1983). A dissolução e absorção do $\mathrm{Al}(\mathrm{OH})_{3}$ é variável mas baixa (Weberg \& Berstad, 1986), enquanto sais solúveis são mais absorvíveis (Froment et al., 1989). 
Menos de $1 \%$ do $\mathrm{Al}$ ingerido é absorvido pelo trato gastrintestinal e retido nos tecidos dos animais, portanto a excreção urinária somente será importante quando o consumo for excessivo (NRC, 2005). Essas características de baixa absorção e boa excreção urinária quando ingerido em excesso, indicam a baixa toxicidade deste elemento para os animais (Suttle, 2010). Testes com ratos e animais de laboratório, ingerindo dieta contendo moderada quantidade de $\mathrm{Al}$ (160 a 335 ppm), excretaram praticamente todo o Al via fezes (McDowell, 1992).

A pequena quantidade de Al que é absorvida ocorre através da mucosa gástrica (nanopartículas) ou no intestino delgado proximal, imediatamente antes da precipitação como hidróxido pela ação de secreções pancreático-biliares (Powell \& Thompson, 1993). A absorção pode ocorrer por meio de processo passivo ou ativo envolvendo proteínas de ligação a metais, inespecíficas da mucosa (NRC, 2005). Nessas situações de absorção ou de administração sistêmica a principal via de excreção do Al observada é a urinária (Alfrey, 1986).

Nos casos em que as excreções fecal e urinária não são suficientes para a eliminação do mineral, o mesmo é absorvido e depositado no fígado, ossos, cérebro, e outros tecidos (NRC, 1980).

O alumínio é classificado como tóxico devido sua atividade biológica estar relacionada a reações tóxicas (McDowell, 1992) porém, sua toxicidade em humanos é considerada relativamente baixa (Underwood, 1977) e de acordo com McDowell (1992) este elemento é facilmente eliminado do corpo pelas fezes.

Em ruminantes a toxidez do Al está altamente associada à deficiência de fósforo, pois a afinidade destes minerais pode resultar na formação de complexos que não são absorvidos pelo intestino (Foy \& Brown, 1963), interferindo na formação óssea. $\mathrm{O}$ Al depositado na mitocôndria dos osteoblastos inibe a formação dos fosfatos ósseos (Lieberherr et al., 1987), tornando os ossos mais frágeis. Contudo, evidências indicam que o acúmulo de $\mathrm{Al}$ pode induzir a regeneração óssea a partir de estímulos a certas enzimas envolvidas no metabolismo do succinato e, é considerado essencial para a fertilidade de ratas (NRC, 1980).

O nível máximo tolerável de um mineral é definido como nível dietético que, quando fornecido por um período limitado não prejudique o desempenho animal e não produza resíduos perigosos na alimentação humana com derivados de animais (NRC, 1980). A idade, condição fisiológica do animal, biodisponibilidade do elemento consumido e sua relação com os outros minerais determinam a ingestão máxima tolerável de $\mathrm{Al}$ (McDowell, 1992). De maneira geral, os bovinos toleram a ingestão máxima de 1000 ppm de sais solúveis de alumínio de alta biodisponibilidade (McDowell, 1992).

Se a ingestão de Al é oriunda de solo, provavelmente apresentará menor biodisponibilidade quando comparado aos sais inorgânicos, assim apresentará menor efeito sobre a disponibilidade do fósforo (Robinson et al., 1984). Além disso, não existem evidências de hipofosfatemia ou má mineralização óssea em animais recebendo dietas com níveis adequados de fósforo, mesmo com a ingestão de solos ricos em alumínio (Suttle, 2010).

As diferentes fontes de $\mathrm{Al}$ conferem diversidade em sua biodisponibilidade e toxicidade potencial. A ingestão de cloreto e lactato de $\mathrm{Al}$ por períodos acima de 24 semanas está associada a redução da atividade da bomba de sódio-potássio (Na-K), aumento na concentração de $\mathrm{Al}$ em várias regiões cerebrais, além de aumento de peroxidação lipídica (Lal et al., 1993; Sarin et al., 1997) que provavelmente resulta em diminuição significativa do conteúdo em lipídios totais, glicolípidios e fosfolípidios, bem como um aumento dos níveis de colesterol e da razão colesterol/fosfolípidios (Sarin et al., 1997).

A atividade da bomba de sódio-potássio é essencial em diversas funções celulares já que os gradientes eletroquímicos de Na e K são importantes para o controle do volume celular, transporte de metabólitos e outras substâncias e para garantir a excitabilidade das células nervosas e musculares (Mobasheri et al., 2000; Jorgensen et al., 2003).

O alumínio é considerado um agente neurotóxico (Yokel, 2000), relacionado a doenças degenerativas como a Doença de Alzheimer (Mjöberg et al., 1997; Exley, 1999; Exley \& Korchazhkina, 2001; Flaten, 2001). Conteúdos de 15 a $30 \mu \mathrm{mol} / \mathrm{Kg}$ de peso seco de cérebro são considerados normais em humanos, sendo observados aumentos de três a dez vezes desse conteúdo em casos de intoxicação (Ganrot, 1986).

\section{EsCOLHA dO ELEMENTO PARA ANÁlISE dO CAULIM}

Como descrito anteriormente, para sabermos o volume de caulim excretado via fezes, é preciso determinar a concentração de algum de seus elementos e a partir desta estimar indiretamente a sua concentração. Desta forma é importante realizar comparações entre os seus possíveis elementos, no que se refere aos aspectos - absorção, via de excreção, contaminação, e técnicas de análises.

A maior concentração de $\mathrm{Si}\left(46,5 \%\right.$ de $\left.\mathrm{SiO}_{2}\right)$ em relação ao $\mathrm{Al}\left(39,5 \%\right.$ de $\left.\mathrm{Al}_{2} \mathrm{O}_{3}\right)$ no caulim (Giese Jr., 1988) pode induzir a escolha do primeiro elemento para estimativas do produto nas fezes pressupondo obter estimativas mais precisas. No entanto, é sabido que ambos elementos apresentam concentrações contaminantes oriundas da ingestão de fontes não controladas durante o pastejo (solo, forragem).

O silício apresenta alta concentração contaminante oriundo de solo, pois é o mineral mais abundante nos solos (Barbosa Filho et al., 2001) e também em forragens, o que exige estratégias de separação e identificação para possibilitar a estimativa do caulim nas fezes.

Por outro lado, o fato do Al de estar presente nas forrageiras em concentração muito pequena leva a acreditar que este elemento é a escolha mais coerente. Apesar da elevada ingestão de solos, 10 a 25\% da ingestão de MS, resulta em Al contaminante na faixa de 0,3 a 1,2\% da matéria seca ingerida por animais em pastejo (Healy et al., 1974; Thornton, 1974). Sendo essa 
concentração incapaz de influenciar qualquer dado ou resultado de avaliação nutricional de animais.

\section{CONCLUSÃO}

O caulim apresenta características que o evidenciam como potencial marcador externo em estudos de consumo e digestibilidade, como ser inerte em ampla faixa de $\mathrm{pH}$, fácil dispersão, baixa condutividade térmica e elétrica, pouca abrasividade, baixo custo e boa resistência ao ataque químico por ácidos ou álcalis. Para a mensuração da substância via fezes, é preciso determinar a concentração de algum de seus elementos, ou seja, pelo fato do alumínio estar presente nas forrageiras em concentração muito pequena, e metodologia analítica mais prática, leva a acreditar que este elemento é a escolha mais coerente.

\section{BIBLIOGRAFIA}

Alexopoulos, C, Papaioannou DS, Fortomaris, Petal. 2007, 'Experimental study on the effect of in-feed administration of a clinoptilolite-rich tuff on certain biochemical and hematological parameters of growing and fattening pigs', Livestock Science, vol. 111, pp. 230-241.

Alfrey, AC 1986, 'Aluminun', in W Mertz (ed.), Trace elements in human and animal nutrition, 5ed, Academic Press, vol. 2, San Diego, Califórnia, EUA, pp. 225-244.

Anderson, DL, Snyder, GH \& Martin, FG 1991, 'Multi-year response of sugarcane to calcium silicate slag on Everglades Histosols', Agron. J., vol. 8, pp. 870-874.

Anonymous Kaolin clay Tolerance Requirement Exemption 1998, Environmental Protection Agency (EPA), Federal Register February 25, vol. 63, no. 37, pp. 9427-9430.

Araújo, KV, Lima, JAF, Fialho, ET, \& Miyagi, ES 2000, 'Comparação dos indicadores internos com o método de coleta total para determinar a digestibilidade dos nutrientes de dietas mistas em equinos', Ciênc. agrotec., vol. 24, no. 4, pp. 1041-1048.

Barbosa Filho, MP, Snyder, GH, Fageria, NK et al. 2001, 'Silicato de cálcio como fonte de silício para o arroz de sequeiro', R. Bras. Ci. Solo, vol. 25, pp. 325-30.

Barros, EEL, Fontes, CAA, Detmann, E et al. 2009, 'Vícios na estimação da excreção fecal utilizando indicadores internos e óxido crômico em ensaios de digestão com ruminantes', Rev. Bras. Zootec., vol. 38, no. 10, pp. 2015-2020.

Berchielli, TT, Andrade, P, Furlan, CL 2000, 'Avaliação de indicadores internos em ensaios de digestibilidade', Rev. Bras. Zootec., vol. 29, no. 3, pp. 830-833.

Berchielli, T, Garcia, AV, Oliveira, SG 2006, 'Principais técnicas de avaliação aplicadas em estudos de nutrição', in: (eds.), Nutrição de ruminantes, FUNEP, Jaboticabal, BRA., pp. 397-421.

Berchielli, T, Garcia, AV, Oliveira, SG 2011, 'Principais técnicas de avaliação aplicadas em estudo de nutrição', in: Berchielli, $\Pi$, Pires, AV, Oliveira, SG (eds), Nutrição de Ruminantes, 2.ed., FUNEP, Jaboticabal, BRA., pp. 565-600.

Bohnert, DW, Harmon DL, Larson BT 2000, Evaluation of four internal markers and an intra-ruminal chromium-releasing device for use in predicting diet digestibility and intake in beef steers, Kentucky Beef Cattle Research Report, Agricultural Experimental Station, College of Agriculture, University of Kentucky, KY (USA), pp. 29-30.

Brebner, J, Thornton, I, McDonald, P \& Suttle, NF 1985, 'The release of trace elements from soils under conditions of simulated rumenal and abomasal digestion', in: Mills, CF, Bremner, I and Chesters, JK (eds), Proceedings of the Fifth International Symposium on Trace Elements in Animals and Man, Commonwealth Agricultural Bureaux, Farnham Royal, UK, pp. 850-852.
Bristow, CM 1987a, 'Kaolin paper underpins current demand', Industrial Minerals, pp. 62-67.

Bristow, CM 1987b, 'World Kaolins - genesis, explotation and application', Industrial Minerais, no. 240, pp. 45-59.

Bordonalli, SP 1995, 'Potencial Técnico e Econômico da Indústria do Caulim: Monitoração e um Ensaio de Projeções para a Próxima Década', 126f, Dissertação (Mestrado), Universidade Estadual de Campinas, Campinas, SP.

Burns, JC, Pond, KR, Fisher, DS 1994 'Measurements of forage intake', in (ed.), Forage quality, evaluation and utilization, American Society of Agronomy, Ohio, EUA, pp. 494-532.

Carretero, MI 2002, 'Clay minerals and their beneficial effects upon human health, A review', Applied Clay Science, vol. 21, pp. 155-163.

Carvalho, PCF, Kozloski, GV, Ribeiro Filho, HMN et al. 2007, 'Avanços metodológicos na determinação do consumo de ruminantes em pastejo', Revista Brasileira de Zootecnia, vol. 36, suplemento especial, pp. 151-170.

Casali, AO et al. 2008, 'Influência do tempo de incubação e do tamanho de partículas sobre os teores de compostos indigestíveis em alimentos e fezes bovinas obtidos pro procedimentos in situ', R. Bras. Zootec., vol. 37, no. 2, pp. 335-342.

Casson, T, Rowe, JB, Thorn, CW, \& Harris, D 1990, 'The use of natural n-alkanes in medic and clover as indigestible markers', Proceedings of the Australian Society of Animal Production, vol. 18, pp.462.

Castro, M \& Elias, A 1978, 'Effect of inclusion of zeolite in final molassesbased diets on performance of growing and fattening pigs', Cuban Journal of Agricultural Science, vol. 12, pp. 69-75.

Cavalcanti, AC et al. 2013, 'Indicadores do metabolismo animal', in (eds.), Compêndio de utilização de indicadores do metabolismo animal, GIL, Belo Horizonte, BRA., pp. 8- 38.

Cezimbra, IM 2010, 'Indicadores na estimativa do fluxo de nutrientes no duodeno, producao fecal, consumo de concentrado e volumoso por bovinos', 65 f, Dissertacao (Mestrado), Universidade Estadual Paulista, Faculdade de Ciências Agrarias e Veterinárias, Jaboticabal, SP.

Coelho Silva, JF, Leão, MI 1979, Fundamento de nutrição de ruminantes, Livroceres, Piracicaba, SP, pp. 384.

Coelho, ACV, Santos, PS, Santos, HS 2007, 'Argilas especiais: argilas quimicamente modificadas - uma revisão', Quim. Nova, vol. 30, no. 5, pp. 1282-1294.

Constantino, VRL, Araki, K, Silva, DO, \& Oliveira, W 2002, 'Preparação de compostos de alumínio a partir da bauxita: considerações sobre alguns aspectos envolvidos em um experimento didático' Quim. Nova, vol. 25, no. 3, pp.490-498.

Côrtes, C, Damasceno, JC, Paine, RC, \& Fukumoto, NM et al. 2005, 'Uso de n-alcanos na estimativa da composição botânica em amostras com diferentes proporções de Brachiaria brizantha e Arachis pintoi', Rev. Bras. Zootec., vol. 34, no. 5, pp. 1468-1474.

Crooker, BA, Clark, JH, Shanks, RD 1982, 'Rare earth elements as markers for rate of passage measurements of individual feedstuffs through the digestive tract of ruminants', J. Nutr., vol. 112, no. 7, pp. 1353-1361.

Criscuolo, PSR 2008, 'Beneficiamento do caulim duro das bacias dos rios Capim e Jari através do processo de agregação seletiva', Dissertação (Mestrado), Universidade Federeal de Minas Gerais, Belo Horizonte, MG.

Delhaize, E \& Ryan, PR 1995, 'Aluminum toxicity and tolerance in plants', Plant Physiology, vol.107, pp.315-321.

Exley C 1999, 'A molecular mechanism of aluminium-induced Alzheimer's disease?', J. Inorg. Biochem, vol. 76, pp. 133-140.

Exley C \& Korchazhkina O 2001, 'The association of aluminum and amyloid in Alzheimer $\bowtie s$ disease', in Exley $C$ (ed.), Aluminium and Alzheimer's disease, The science that describes the link, chapter 22, Elsevier Science, pp. 421-433.

Faquin, V 2005, 'Nutrição mineral de plantas', 186 f, Especialização, Universidade Federal de Lavras, Lavras, MG.

Fahey JR, GC \& Jung, HG 1983, 'Lignin as a marker in digestion studies: a review', J.Anim. Sci. vol. 57, no. 1, pp.220-225. 
Flaten TP 2001, 'Aluminium as a risk factor in Alzheimer's disease, with emphasis on drinking water', Brain Res. Bull, vol. 55, pp.187-196.

Foy, CD, Brown, JC 1963, 'Toxic factor in acid soil: I. Characterization ef aluminum toxicity in cotton', Soil Sci. Soc. Amer. Proc., vol. 27, pp. 403-407.

Froment, DH, Buddington, B, Miller, NL, \& Alfrey, AC 1989, 'Effect of solubility on the gastrointestinal absorption of aluminium from various aluminium compounds in the rat', Journal of Laboratory and Clinical Medicine, vol. 114, pp.237-242.

Fukushima, RS \& Hatfield, DR 2003, 'Composição fenólica de ligninas dioxano determinadas pela reação oxidadtiva com o nitrobenzene', Pesq. Agropec. Bras., vol. 38, no. 3, pp.373-378.

Ganrot, PO 1986, 'Metabolism and possible health effects of aluminium', Environ Health Perspect, vol. 65, pp. 363-441

Giese Jr, RF 1988, 'Kaolin minerals: structures and stabilities', in SW Bailey (ed.), Review in Mineraloy: Hydrous Phyllosilicates, Chelsea, Michigan, EUA, vol. 19, pp. 29-66

Goldberg, S 1989, 'Interaction of aluminum and iron oxides and clay minerals and their effect on soil physical properties: a review', Comm. Soil Sci. Plant Anal., vol. 20, pp. 1181-1207.

Healy, WB, Rankin, PC, Watts, HM 1974, 'Effect of soil contamination on the element composition of herbage', New Zealand Journal of Agricultural Research, vol. 17, pp. 59-61.

Ítavo, LCV 2001, 'Consumo, digestibilidade e eficiência microbiana de novilhos alimentados com dietas contendo vários níveis de concentrado, utilizando diferentes indicadores e períodos de coleta', $114 \mathrm{f}$, Tese (Doctor Scientiae), Universidade Federal de Viçosa, Viçosa, MG.

Ítavo, LCV, Souza, SRMBO, Rímoli, J, Ítavo, CCBF et al. 2008, 'Comportamento ingestivo diurno de bovinos em pastejo contínuo e rotacionado', Arch. Zootec. vol. 57, no. 217, pp. 43-52.

Jorgensen, PL, Hakansson, KO \& Karlish SJ 2003, 'Structure and mechanism of Na,K-ATPase: functional sites and their interactions', Annu. Rev. Physiol., vol. 65, pp. 817-849.

Khawmee, K, Suddhiprakarn, A, Kheoruenromne, I, \& Singh, B 2013, 'Surface charge properties of kaolinite from Tai soils', Geoderma, vol. 192, pp. 120-131.

Kozloski, GV, Netto, DP, Oliveira, Let al. 2006, 'Uso do óxido de cromo como indicador da excreção fecal de bovinos em pastejo: variação das estimativas em função do horário de amostragem', Ciênc. Rural, vol. 36, pp. 599-603.

Kozloski, GV, Mesquita, FR, Alves, TP et al. 2009, 'Avaliação do uso de frações indigestíveis do alimento como indicadores internos de digestibilidade em ovinos', R. Bras. Zootec., vol. 38, no. 9, pp.1819-1823.

Lal, B, Gupta, A, Murthy, RC et al. 1993, 'Aluminum ingestion alters behaviour and some neurochemicals in rats', Indian J. Exp. Biol. vol. 31, pp. 30-35.

Lanzetta, VAS, Rezende, ASC, Saliba, EOS et al. 2009, 'Validação do Lipe $\AA^{\circledR}$ como método para determinar a digestibilidade dos nutrientes em equinos', R. Bras. Zootec., vol. 38, no. 1, pp.69-74.

Laredo, MA, Simpson, GD, Minson, DJ, \& Orpin, CG 1991, 'The potential for using n- alkanes in tropical forages as a marker for determination of dry matter by grazing ruminants', Journal of Agricultural Science, vol. 117, pp. 355-361

Lieberherr, M, Grosse, B, Cournot-Wltmer, G 1987, 'Aluminum action on mouse bone cell metabolism and response to PTH and 1, 25(OH)2D3', Kidney International, vol. 31, pp. 736-743.

Lote, CJ, Saunders, H 1991, 'Aluminium: gastrointestinal absorption and renal excretion', Clinical Science, vol. 81, pp. 289-295.

Luz, AB \& Damasceno, EC 1993, Caulim: Um mineral industrial importante, Série Tecnologia Mineral, CETEM/CNPq, Rio de Janeiro, RJ, no. 65, pp. 29.

Luz, AB, Carvalho, EA, Bertolino, LC et al. 2009, Caulim, Comunicação Técnica-Elaborada para o livro Rochas \& Minerais Industriais: usos e especificações, 2 ed., CETEM/MCT, Rio de Janeiro, RJ, pp. 255-294.

$\mathrm{Ma}$, JF 2000, 'Role of organic acids in detoxification of aluminum in higher plants', Plant Cell Physiol., vol. 41, no. 4, pp. 383-90.
Ma, JF, Miyake, Y, Takahashi, E 2001, 'Silicon as a beneficial element $\mathrm{fr}$ crop plants' in Datnoff, LE, Sneder, GH, Korndorfer, GH (ed,), Silicon in Agriculture, Elsevier, Amsterdam, NL, pp.17-39.

Marais, JP 2000, 'Use of markers', in D'Mello, JPF (ed.), Farm animal metabolism and nutrition: critical reviews, The Scottish Agricultural College, Edimburgo, Reino Unido, pp. 255-277.

Matlova, L, Dvorska, L, Bartos, M et al. 2004, 'Tuberculous lesions in pig lymphnodes caused by kaolin fed as supplement', Veterinarni Medicina, vol. 49, pp.379-388.

Mauras, Y, Renier, JC, Tricard, A, \& Allain, P 1983, 'Mise en evidence de I'absorption gastro-intestinale du silicium a partir d'un aluminosilicate (Evidence for the gastrointestinal absorption of silicon from an aluminosilicate)', Therapie, vol. 38, pp. 175-178.

Mayes, RW, Lamb, CS 1984, 'The possible use of n-alkanes in herbage as indigestible faecal markers', Proceedings of the Nutrition Society, Abstracts of Communications,, vol. 43, pp. 39.

Mayes, RW, Lamb, CS, Colgrove, PM 1986, 'The use of dosed and herbage $n$-alkanes as markers for the determination of herbage intake', Journal Agriculture Science, vol. 70, no. 1, pp. 161-170.

McDowell, LR 1992, Minerals in animal and human nutrition, Academic Press, Inc., San Diego, CA, pp. 352-365.

Mengel, KE \& Kirkby, GA 1987, 'Further elements of importance', in Principles of plant., 4.ed., International Potash Institute, WorblaufenBern, Suíça, pp. 573-588.

Miller, RG, Kopfler, FC, Kelty, KC et al. 1984, 'The occurrence of aluminum in drinking water. J. Am', Water Works Assoc., vol. 76, pp. 84-91.

Mir, PS, Kalnin, CM, Garvey, SA 1989, 'Recovery of fecal chromium used as a digestibility marker in cattle', J. Dairy Sci., vol. 72, pp. 2549-2553.

Miöberg, B, Helquist, E, Mallmin, H, \& Lindh, U 1997, 'Aluminium, Alzheimer's disease and bone fragility', Acta Orthop. Scand., vol. 68, pp. 511-514.

Mobasheri, A, Avila, J, Cozar-Castellano, I, Brownleader, MD, et al. 2000, 'Na+,K+-ATPase isozyme diversity; comparative biochemistry and physiological implications of novel functional interactions', Biosci. Rep., vol. 20, pp. 51-91.

Monte, MBM, Carvalho, EA, Ferreira, O \& Cabo, SS 2001, 'Caulim CADAM', in Usinas de Beneficiamento de Minérios do Brasil, Editores: João A. Sampaio, Adão B. da Luz e Fernando F Lins, 398p, CETEM/MCT, pp. 9-23.

Morenz, MJF, Da Silva, JFC, Aroeira, LM et al. 2006, 'Óxido de cromo e alcanos na estimativa do consumo de forragem de vacas em lactação em condições de pastejo'. R. Bras. Zootec., vol. 35, no. 4, pp. 1535-1542.

Murray, HH 2000, 'Traditional and new applications for kaolin, smectite, and palygorskite: a general overview', Appl. Clay Sci., vol. 17, pp. 207-221.

Murray, HH \& Kogel, JE 2005, 'Engineered clay products for the paper industry', Appl.Clay Sci. vol. 29, pp. 199-206.

Murray, HH 2007, 'Kaolin applications', in Murray, HH (ed.), Applied Clay Mineralogy, Occurrences, Processing and Application of Kaolins, Bentonites, Palygorskite-Sepiolite, and Common Clay, Elsevier, Amsterdam, Holanda, pp. 85-109.

NRC - National Research Council 1980, Mineral tolerance of domestic animals, National Academic Press, Washington, DC, pp. 577.

NRC - National Research Council 1981, Effect of Environmenton Nutrient Requirements of Domestic Animals, National Academy of Sciences, Washington, DC, pp. 169

NRC - National Research Council 1987, Predicting Feed Intake of FoodProducing Animals, National Academy of Sciences, Washington, DC, pp. 85.

NRC - National Research Council 2005, Mineral Tolerances of Animals, 2a ed., National Academy Press, Washington, DC.

Oliveira, LOF, Saliba, EOS, Amaral, TB, et al. 2004, 'Avaliação de diferentes períodos de oferecimento de óxido crômico como marcador externo nas estimativas de consumo para bovinos', in Reunião Anual Da Sociedade Brasileira De Zootecnia, 41, Campo Grande, Anais [sn] 2004, Campo Grande, MS. 
Oliveira, LOF 2005, 'Desempenho, consumo, dinâmica ruminal e cinética da degradação da Brachiaria brizantha cv Marandu, em bovinos de corte suplementados com proteinados', 94 f, Tese (Doutor em Ciência Animal), Universidade Federal de Minas Gerais, Escola de Veterinária, Belo Horizonte, MG.

Oliveira, LOF, Santos, SA, Abreu, UGP 2012a, 'Uso de indicadores nos estudos de nutrição animal aplicados aos sistemas de produção a pasto', Documento 120, Embrapa Pantanal, Corumbá-MS, pp. 25.

Oliveira, K, Bittar, CMM, Costa, $C$ et al. 2012b, 'Fezes equina como fonte de inóculo na obtenção de indicadores indigestíveis para estimar a digestibilidade em equinos', Rev. Bras. Saúde Prod. Anim., vol. 13, no. 2, pp. 410-423.

Owens, FN \& Hanson, CF 1992, 'Symposium: External and internal markers for appraising site and extent digestion in ruminants', J. Dairy Sci., vol. 75, no. 9, pp. 2605-2617.

Papaioannou, D, Katsoulos, PD, Panousis, N, \& Karatzias, H 2005, 'The role of natural and synthetic zeolites as feed additives on the prevention and/or the treatment of certain farm animal diseases: A review', Microporous and Mesoporous Materials, vol. 84, pp. 161-170.

Pedrotti, A, Ferreira, MM, Curi, $N$ et al. 2003, 'Relação entre atributos físicos, mineralogia da fração argila e formas de alumínio no solo', R. Bras. Ci. Solo, vol. 27, pp. 1-9.

Piaggio, LM, Prates, ER, Pires, FF, \& Ospina, H 1991 'Avaliação das cinzas insolúveis em ácido, fibra em detergente ácido indigestível e lignina em detergente ácido indigestível como indicadores internos da digestibilidade', R. Bras. Zootec., vol. 20, no. 3, pp. 306-312.

Pombo, GV, Valle, TD, Bradi, RA, \& Bueno, ICS 2016, 'Acurácia, precisão e robustez de indicadores internos para predição da digestibilidade aparente total de matéria seca em equinos', Arq. Bras. Med. Vet. Zootec., vol. 68, no. 3, pp. 769-775.

Powell, JJ \& Thompson, PH 1993, 'The chemistry of aluminium in the gastrointestinal lumen and its uptake and absorption', Proceedings of the Nutrition Society, vol. 52, pp. 241-253.

Rebouças, GMN, Silva, FA, Silva, CRM 2013, 'Fibras indigestíveis', in (eds.), Compêndio de utilização de indicadores do metabolismo animal, Gil, Belo Horizonte, MG, pp.97-123.

Resende, M 1985, 'Aplicações de conhecimentos pedológicos à conservação de solos', Inf. Agropec., vol. 11, pp. 3-18.

Robinson, DL, Hemkes, OJ, Kemp, A 1984, 'Relationships among forage aluminium levels, soil contamination on forages and availability of elements to dairy cows', Netherlands Journal of Agricultural Science, vol. 32, pp. 73-80.

Rodrigues, PHM, Gomes, RC, Siqueira, RF et al. 2010, 'Acurácia, precisão e robustez das estimativas da digestibilidade aparente da matéria seca determinada com o uso de indicadores em ovinos', $R$. Bras. Zootec., vol. 39, no. 5, pp. 1118-1126.

Rugmini, S \& Menon, ARR 2008, 'Organomodified kaolin as filler for natural rubber', J. Appl. Polym. Sci., vol. 107, pp. 3476-3483.

Saliba, EOS, Rodriguez, NM, Gonçalves, LC, \& Fernandes, PCC 1999, 'Effect of corn and soybean lignin residues submitted to the ruminal fermentation on structural carbohydrates digestibility', Arq. Bras. Med. Vet. Zootec., vol. 51, no. 1, pp. 85-88.

Saliba, EOS, Rodriguez, NM, Gonçalves, LC et al. 2002, 'Lignina isolada da palha do milho utilizada como indicador em ensaios de digestibilidade, Estudo comparative', Arq. Bras. Med. Vet. Zootec. vol. 54, no. 1, pp. 52-54

Saliba, EOS 2013, 'Lignina purificada e enriquecida LIPE', in (eds.), Compêndio de utilização de indicadores do metabolismo animal, Gil, Belo Horizonte, MG, p. 179-192.

Saliba, EOS, Faria, EP, Rodriguez, NM et al. 2015, 'Use of infrared spectroscopy to estimate fecal output with marker Lipe $\AA^{\prime}$, J Food Sci Nutr Diet, vol. 4, no. 1, pp. 1-10.

Sampaio, CR, Detmann, E, Valente, TNP et al. 2011 a, 'Evaluation of fecal recovering and long term bias of internal and external markers in a digestion assay with cattle', R. Bras. Zootec., vol. 40, no. 1, pp. 174-182.
Sampaio, CR, Detmann, E, Valente, TNP et al. 2011 b, 'Fecal excretion patterns and short term bias of internal and external markers in a digestion assay with cattle', R. Bras. Zootec., vol. 40, no. 3, pp. 657-665.

Santos, PS 1975, Tecnologia de argilas - aplicado a argilas brasileiras, Ed. Edgard Blucher, São Paulo, SP, pp. 802.

Santos, FC dos 2009, 'Silício orgânico: muito além da estética', Revista Biotec, no. 2, pp. 16.

Sangster, AG, Hodson, MJ, Parry DW 2001, 'Silicon deposition and anatomical studies in the inflorescence bracts of four Phalaris species with their possible relevance to carcinogenesis', New Phytologist, vol. 93, pp. 105-122.

Sarin, S, Gupta, V, Gill, KD 1997, 'Alterations in lipid composition and neuronal injury in primates following chronic aluminium exposure', Biol. Trace Elem. Res., vol. 59, pp. 133-143.

Silva, SP 2001, Caulim, Balanço Mineral Brasileiro, Departamento Nacional de Produção Mineral (DNPM), Disponível em: <http:// www.dnpm.gov.br/assets/galeriadocumento/balancomineral2001/ caulim.pdf $>$.Acessado em: 10/08/2012.

Silva, FANG 2007, 'Estudos de Caracterização Tecnológica e Beneficiamento do Caulim da Região Borborema - Seridó', 86f, Dissertação (Mestrado) - COPPE, Universidade Federal do Rio de Janeiro, RJ.

Silva, FA \& Costa, HHA 2013, 'Terras Raras', in Saliba, EO, Cavalcanti, AC (eds.), Compêndio de utilização de indicadores do metabolismo animal, Gil, Belo Horizonte, MG, pp. 245-255.

Siqueira, RF, Gomes, RC, Rodrigues, PHM et al. 2009, 'Uso da cutina na estimativa da digestibilidade aparente de dietas para equinos', Arq. Bras. Med. Vet. Zootec., vol. 61, no. 6, pp. 1373-1381.

Soares, JPG, Berchielli, TT, Aroeira, LM et al. 2004, 'Estimativas de Consumo do Capim-Elefante (Pennisetum purpureum Schum), Fornecido Picado para Vacas Lactantes Utilizando a Técnica do Óxido Crômico', R. Bras. Zootec., vol. 33, no. 3, pp. 811-820.

Soares, LFP, Guim, A, Modesto, EC et al. 2011, 'Uso do LIPE $®$ e do Óxido de Cromo na Estimativa do Consumo de Matéria Seca por Bubalinos', Rev. Cient. Prod. Anim., vol. 13, no. 1, pp. 80-83.

Soeiro, ER 2014, Caulim, Sumário Mineral 2014, Departamento Nacional de Produção Mineral (DNPM), Disponível em: < http://www. dnpm.gov.br/dnpm/sumarios/sumario-mineral- 2014>. Acessado em: 14/10/2016

Stewart, WK 1989, 'Aluminium toxicity in individuals with chronic renal disease', in Massey, RC, Taylor, D (eds.), Aluminium in Food and the Environment, Royal Society of Chemistry, London, UK, pp. 7-19.

Suttle, NF 2010, Mineral nutrition of livestock, 4 ed., Cabi, British Library, London, UK, pp. 587.

Teixeira, GK 2015, 'Caracterização mineralógica do caulim: aplicação em perfis dos depósitos do rio Capim (PA)', 68f, Dissertação (Mestrado), Instituto de Geociência - Universidade Federal do Rio Grande do Sul, Porto Alegre, RS.

Trckova, M, Vondruskova, H, Zraly, Z et al. 2009, 'The effect of kaolin feeding on efficiency, health status and course of diarrhoeal infections caused by enterotoxigenic Escherichia coli strains in weaned piglets', Veterinarni Medicina, vol. 54, no. 2, pp. 47-63.

Thonney, ML, Palhof, BA, De Carlo, MR et al. 1984, 'Sources of variation of dry matter digestibility measured by the acid insoluble ash marker', J. Dairy Sci., vol. 68, no. 3, pp. 661-668.

Thornton, I 1974, 'Biogeochemical and soil ingestion studies in relation to the trace-element nutrition of livestock', in Hoekstra, WG, Suttie, JW, Ganther, HE \& Mertz, W (eds.), Trace Element Metabolism in Animals-2, University Park Press, Baltimore, Maryland, pp.451- 454.

Tisdale, SL, Nelson, WL, Beston, JD \& Haulin, JL 1993, Soil fertility and fertilizer, Macmillam, New York, NK, p.634

Titgemeyer, EC, Armendariz, CK, Bindel, DJ et al. 2001, 'Evaluation of titanium dioxide as a digestibility marker for cattle', J. Animal Sci., vol. 79, no. 4, pp. 1059-1063.

Underwood, EJ 1977, Trace Elements in Human and Animal Nutrition, 4, Academic Press, New York, NY, pp. 430-432.

Van Soest, PJ 1994, Nutritional ecology of the ruminant, 2 ed., Cornell University Press, Ithaca, NK, pp. 476. 
Vimonses, V, Lei, S, Jin, BO \& Saint, C 2009, 'Kinetic study and equilibrium isotherm analysis of Congo red adsorption by clay materials', Chem. Eng. J., vol. 148, pp. 354-364.

Xiang, D \& Gu, C 2006, 'A study on the friction and wear behavior of PTFE filled with ultra-fine kaolin particulates', Mater. Lett., vol. 60, pp. 689-692.

Wada, K \& Harward, NE 1974, 'Amorphous clay constituents of soils', Adv. Agron., vol. 26, pp. 211-260.

Weberg, R \& Berstad, A 1986, 'Gastrointestinal absorption of aluminium from single doses of aluminium containing antacids in man', European Journal of Clinical Investigation, vol. 16, pp. 428-432.

Wilson, IR, Santos, HS, Santos, PS 1998, 'Caulins brasileiros: alguns aspectos de geologia e da mineralogia', Cerâmica, vol. 44, pp. 287-288.
Witte, GJ 1993, An introduction to china clay (kaolin) - geology, mineralogy and production, WBB Fact Sheet n.2, Watts Blake \& Bearne Co. Plc, Devon, UK, pp. 9.

Yokel, RA 2000, 'The toxicology of aluminum in the brain: a review', Neurotoxicology, vol. 21, pp. 813-28.

Zeoula, LM, Prado, IN, Caldas Neto, SF et al. 2000, 'Substituição do milho pela farinha de varredaura de mandioca (Manihot esculenta, Crantz) sobre o consumo voluntário e digestibilidade em ovinos', in Reunião Anual Da Sociedade Brasileira De Zootecnia, vol. 37, Viçosa, Anais 2000 SBZ, Viçosa, MG.

Zeoula, LM, Prado, IN, Dian, PHM et al. 2002, 'Recuperação fecal de marcadores internos avaliados em ruminantes', Rev. Bras. Zootec., vol. 31, no. 4, pp. 1865-1874. 